\title{
Characterization of multidrug-resistant and extended-spectrum $\beta$-lactamase-producing Klebsiella pneumoniae strains from Malaysian hospitals
}

\begin{abstract}
Correspondence
Kwai Lin Thong

thongkl@um.edu.my
\end{abstract}

Received 23 March 2009

Accepted 9 July 2009

\author{
King Ting Lim, ${ }^{1}$ Chew Chieng Yeo, ${ }^{2}$ Rohani Md Yasin, ${ }^{3}$ Ganeswrie Balan ${ }^{4}$ \\ and Kwai Lin Thong ${ }^{1}$ \\ ${ }^{1}$ Institute of Biological Science, Faculty of Science, University of Malaya, 50603 Kuala Lumpur, \\ Malaysia \\ ${ }^{2}$ Faculty of Agriculture and Biotechnology, Universiti Darul Iman Malaysia, 20400 Kuala \\ Terengganu, Malaysia \\ ${ }^{3}$ Specialized Diagnostic Centre, Institute of Medical Research, Jalan Pahang, 50588 Kuala Lumpur, \\ Malaysia \\ ${ }^{4}$ Hospital Sultanah Aminah Johor Bharu, 80100 Johor Bharu, Malaysia
}

The emergence of multidrug-resistant (MDR) and extended-spectrum $\beta$-lactamase (ESBL)producing Klebsiella pneumoniae poses a serious antibiotic management problem as resistance genes are easily transferred from one organism to another. Fifty-one strains of $K$. pneumoniae isolated from sporadic cases in various hospitals throughout Malaysia were analysed by antimicrobial susceptibility testing, PCR detection of ESBL-encoding genes and DNA fingerprinting. Although 27 of the 51 K. pneumoniae strains were MDR (i.e. resistant to three or more classes of antibiotics), the majority of the strains (98\%) were sensitive to imipenem. PCR detection using ESBL gene-specific primers showed that 46 of the $K$. pneumoniae strains

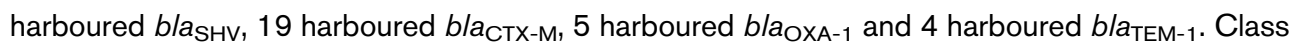
1 integron-encoded int/1 integrase was detected in 21 of the $51 \mathrm{~K}$. pneumoniae strains and amplification of the integron $5^{\prime} \mathrm{CS}$ region showed the presence of several known antibiotic resistance gene cassettes of various sizes. Results of conjugation and transformation experiments indicated that some of the ESBL-encoding genes (i.e. bla $a_{\mathrm{SHV}}$, b/a $a_{\mathrm{CTX}-\mathrm{M}}$ and b/a $a_{\mathrm{TEM}-1}$ ) were transmissible and were likely plasmid-encoded. DNA fingerprinting using PFGE and PCR-based methods indicated that the $51 \mathrm{~K}$. pneumoniae strains were genetically diverse and heterogeneous.

\section{INTRODUCTION}

Klebsiella pneumoniae is an important bacterial pathogen associated with community and nosocomial infections especially in immunocompromised patients (Podschun \& Ullmann, 1998). K. pneumoniae strains have the potential to cause severe morbidity and mortality, particularly in intensive care units and paediatric and surgical wards (BenHamouda et al., 2003).

\footnotetext{
Abbreviations: DDST, double-disc synergy test; ERIC-PCR, enterobacterial repetitive intergenic consensus PCR; ESBL, extended-spectrum $\beta$ lactamase; MDR, multidrug resistant; RAPD, random amplification of polymorphic DNA; REP-PCR, repetitive-sequence-based PCR.

A table listing the primers and PCR cycling parameters is available with
} the online version of this paper.
The emergence of extended-spectrum $\beta$-lactamase (ESBL) producers along with multidrug-resistant (MDR) isolates poses a serious problem in the hospital setting. Since the first report of ESBL-producing Klebsiella in 1983 from a patient in Germany, several outbreaks caused by this pathogen have been reported worldwide (Bradford, 2001; Ben-Hamouda et al., 2003; Jarlier et al., 1988; Livermore et al., 2007; Romero et al., 2007).

The widespread use of antibiotics coupled with the transmissibility of resistance determinants mediated by plasmids, transposons and gene cassettes in integrons are factors that contribute to the increase in antibiotic resistance in bacterial pathogens (Kang et al., 2005). In Malaysia, Palasubramaniam et al. (2005) reported an association of ESBL SHV-5 K. pneumoniae with a nosocomial outbreak in a paediatric oncology unit in a Malaysian public hospital. 
Rapid and discriminative subtyping methods are useful for determining the clonality of the strains in nosocomial outbreaks. Several methods are available for K. pneumoniae subtyping and these include biotyping, serotyping, arbitrarily primed PCR, ribotyping and PFGE (Ben-Hamouda et al., 2003; Cartelle et al., 2004; Singh et al., 2006).

The objectives of this study were to determine the antimicrobial resistance profiles of $K$. pneumoniae strains isolated from various hospitals in Malaysia and to study their genetic diversity using PFGE as well as the PCR-based fingerprinting methods random amplification of polymorphic DNA (RAPD), repetitive-sequence-based (REPPCR) and enterobacterial repetitive intergenic consensus PCR (ERIC-PCR). The presence of several ESBL-encoding genes and integrons was also determined by PCR and their transmissibility was examined by conjugation and transformation experiments.

\section{METHODS}

Bacterial strains. The bacterial strains selected in this study were 51 non-repeat K. pneumoniae strains from 51 different patients obtained from five public hospitals located in Peninsular Malaysia in the year 2004. The participating hospitals included Kota Bharu Hospital $(n=25)$, Ipoh Hospital $(n=3)$, Kuala Lumpur Hospital $(n=1)$, Tuanku Ampuan Rahimah Hospital $(n=2)$ and Sultanah Aminah Hospital $(n=20)$. The strains were cultured from tracheal aspirates $(n=21)$, urine $(n=2)$, sputum $(n=1)$, catheter tips $(n=2)$, blood $(n=1)$, pus $(n=1)$ and swab samples $(n=3)$; there were 20 unknown cultures. The 20 unknown cultures were tagged as such because the exact culture sites were not stated by the respective hospitals and should thus be noted as a limitation for this study. The strains were identified by standard biochemical methods by the microbiologists from the respective hospitals.

All strains were cultured in Luria-Bertani broth and stored in cryovials with $50 \%$ glycerol (Invitrogen) at $-20{ }^{\circ} \mathrm{C}$ and $-85{ }^{\circ} \mathrm{C}$. The purity of the strains was checked before commencement of analysis.

Antimicrobial susceptibility testing and screening for ESBLs. The susceptibilities of the K. pneumoniae strains to 18 antimicrobial agents [ampicillin $(10 \mu \mathrm{g})$, piperacillin $(100 \mu \mathrm{g})$, amoxicillin-clavulanic acid $(20 \mu \mathrm{g} / 10 \mu \mathrm{g})$, ceftriaxone $(30 \mu \mathrm{g})$, ceftazidime $(30 \mu \mathrm{g})$, cefepime $(30 \mu \mathrm{g})$, cefoperazone $(75 \mu \mathrm{g})$, aztreonam $(30 \mu \mathrm{g})$, imipenem $(10 \mu \mathrm{g})$, amikacin $(30 \mu \mathrm{g})$, streptomycin $(10 \mu \mathrm{g})$, gentamicin $(10 \mu \mathrm{g})$, kanamycin $(30 \mu \mathrm{g})$, tetracycline $(30 \mu \mathrm{g})$, chloramphenicol $(30 \mu \mathrm{g})$, ciprofloxacin $(5 \mu \mathrm{g})$, trimethoprim-sulfamethoxazole $(75 \mu \mathrm{g})$ and nalidixic acid $(30 \mu \mathrm{g})$ (Oxoid)] were determined by the disc diffusion method in accordance with the Clinical and Laboratory Standards Institute (CLSI) guidelines (CLSI, 2006).

All strains were screened for ESBL production using ceftriaxone, ceftazidime and aztreonam discs as recommended by the CLSI (2006). Double-disc synergy tests (DDSTs) were performed according to Jarlier et al. (1988) using ceftazidime, ceftriaxone, aztreonam, cefepime and amoxicillin-clavulanic discs. A phenotypic confirmatory test was performed with $30 \mu \mathrm{g}$ ceftazidime [30/10 $\mu \mathrm{g}$ ceftazidime-clavulanic acid, 30/10 $\mu \mathrm{g}$ cefotaxime-clavulanic acid (Becton Dickinson)] and $30 \mu \mathrm{g}$ cefotaxime (Oxoid) discs on Mueller-Hinton agar. The results were interpreted as described by the CLSI (2006). Escherichia coli strains ATCC 25922 and ATCC 35218, K. pneumoniae ATCC 700603 and Pseudomonas aeruginosa ATCC 27853 were used as quality control strains for the antibiotic susceptibility test as recommended by the CLSI (2006).

PCR detection of ESBL-encoding bla $a_{\mathrm{TEM}}, b / a_{\mathrm{SHV}}, b / a_{\mathrm{OXA}}$, bla $a_{\text {CTX-M, }}, b / a_{\text {DHA }}, b / a_{\text {IMP }}, b / a_{\text {VIM }}$ and bla integron-associated genes. A boiled suspension of bacterial cells and extracted plasmid DNA were used as DNA templates. Primers for the detection of ESBL-encoding genes (obtained from Operon Biotechnologies) were applied to the DNA template. Amplification was performed in a final volume of $25 \mu \mathrm{l}$ containing $0.3 \mu \mathrm{M}$ each primer, $35 \mu \mathrm{M}$ each dNTP, $1.4 \mathrm{mM} \mathrm{MgCl}_{2}$ and $0.5 \mathrm{U}$ Taq DNA polymerase (Promega). The cycling parameters used were as previously described (Oliver et al., 2002; Pagani et al., 2003; Pai et al., 2004; Jiang et al., 2006; Giakkoupi et al., 2003; Senda et al., 1996; Machado et al., 2005) (please refer to Supplementary Table S1 in JMM Online for a list of primers and cycling parameters). Primers $1 \mathrm{R}, 1,8 \mathrm{~F}, 2 \mathrm{~F}, 2 \mathrm{R}, 8 \mathrm{R}, 9 \mathrm{~F}$ and $9 \mathrm{R}$ (Ensor et al., 2007) were used for the further subgrouping of the $b l a_{\mathrm{CTX}-\mathrm{M}}$ gene into CTX-M groups 1, 2, 8/ 25 and 9 whereas primers CTX-M1R and CTX-M1F (Conceição et al., 2005 ) were used to confirm the presence of $b l a_{\mathrm{CTX}-\mathrm{M}-15}$ by sequencing the resulting 876 bp amplicon. Detection of class 1, 2 and 3 integronencoded integrases and associated gene cassettes was similarly carried out by PCR using established primers and amplification conditions listed in Supplementary Table S1. Amplified products were sequenced to validate their identity.

E. coli ATCC 352183 and K. pneumoniae ATCC 700603 were used as positive controls for $b l a_{\mathrm{TEM}}$ and $b l a_{\mathrm{SHV}}$. However, no positive controls were available for the detection of $b l a_{\mathrm{OXA}}, b l a_{\mathrm{VEB}}, b l a_{\mathrm{DHA}}$, $b l a_{\mathrm{IMP}}, b l a_{\mathrm{VIM}}$ and $b l a_{\mathrm{CTX}-\mathrm{M}}$ genes as well as for the further subgrouping of the CTX-M group. Therefore, negative results should be treated with caution.

Genotyping by RAPD, REP-PCR, ERIC-PCR and PFGE. RAPD analysis was performed using the primer OPAB11 (Latha et al., 2004). The amplification reaction was carried out in a $25 \mu \mathrm{l}$ volume containing $2.5 \mathrm{mM} \mathrm{MgCl} 2,50 \mu \mathrm{M}$ each deoxynucleoside triphosphate, $0.3 \mu \mathrm{M}$ of the selected primer, $5 \mu \mathrm{l}$ crude DNA template and 1.5 U Taq DNA polymerase (Promega). ERIC- and REP-PCR analyses were performed using the ERIC-2 (de Bruijn, 1992) and REP (Navia et al., 1999) primers, respectively. Amplification reactions were carried out in a $25 \mu$ l volume containing $2.5 \mathrm{mM} \mathrm{MgCl}_{2}, 50 \mu \mathrm{M}$ each deoxynucleoside triphosphate, $0.5 \mu \mathrm{M}$ of the selected primer, $5 \mu \mathrm{l}$ crude DNA template and $1.0 \mathrm{U}$ Taq DNA polymerase (Promega). Following PCR, $10 \mu \mathrm{l}$ aliquots of each sample were subjected to electrophoresis on $1.5 \%$ agarose gels.

PFGE was performed according to previously published work (Thong et al., 2007) with minor variations. Briefly, equal volumes of $1 \%$ Seakem Gold agarose (Cambrex Bio Science) and standardized cell suspension $\left(\mathrm{OD}_{610}=1.4\right)$ were mixed to form agarose plugs. The bacteria were lysed within the plugs with cell lysis buffer [50 mM Tris, $50 \mathrm{mM}$ EDTA (pH 8.0), $1 \%$ Sarcosine, $1 \mathrm{mg}$ proteinase $\mathrm{K} \mathrm{ml}^{-1}$ ] and incubated at $54{ }^{\circ} \mathrm{C}$ for $3 \mathrm{~h}$. The agarose-embedded chromosomal DNA was digested with $10 \mathrm{U} X b a \mathrm{I}$ followed by separation on a CHEF-DRIII system (Bio-Rad) in $0.5 \times$ Tris-borate-EDTA at $14{ }^{\circ} \mathrm{C}$ for $22 \mathrm{~h}$ with pulse times of 1-40 s. Gels were photographed under UV light after staining with $0.5 \mu \mathrm{g}$ ethidium bromide $\mathrm{ml}^{-1}$.

Analysis of fingerprint profiles. The banding patterns generated by RAPD, ERIC-PCR, REP-PCR and PFGE were analysed with GelCompar II, version 2.5 (Applied Maths), and a cluster analysis based on the unweighted pair group method with arithmetic averages with a position tolerance of 0.15 was carried out. All PCR fingerprints and PFGE profiles were assigned an arbitrary designation and analysed by defining a similarity (Dice) coefficient, $F$ (Thong et al., 2007). 
Transfer of resistance determinants and plasmid analysis. Transfer of resistance genes by conjugation was assayed by mating experiments in Luria-Bertani broth using E. coli JM109 [endA1, recA1, gyrA96, thi, hsdR17 $\left(\mathrm{r}_{\mathrm{k}}^{-}, \mathrm{m}_{\mathrm{k}}^{+}\right), \lambda^{-}, \operatorname{relA1}, \operatorname{supE} 44, \Delta($ lac-proAB $)$, ( $\mathrm{F}^{\prime}$, $\operatorname{traD} 36$, $\operatorname{pro} A B$, $\left.\operatorname{lacl}^{\mathrm{q}} \mathrm{Z} \Delta \mathrm{M} 15\right)$ ] (Promega), which is resistant to nalidixic acid, as the recipient strain. Transconjugants were selected on Luria-Bertani agar supplemented with ampicillin $\left(100 \mu \mathrm{g} \mathrm{ml}^{-1}\right)$ plus nalidixic acid $\left(100 \mu \mathrm{g} \mathrm{ml}^{-1}\right)$ (Sigma Aldrich).

For transformation experiments, plasmid DNA from the ESBLproducing K. pneumoniae strains obtained using the QIAprep Spin Miniprep kit (Qiagen) were electroporated into streptomycinresistant E. coli DH10B (Invitrogen). Transformants were selected on Luria-Bertani agar plates supplemented with ampicillin $(100 \mu \mathrm{g}$ $\left.\mathrm{ml}^{-1}\right)$.

For the estimation of plasmid sizes, plasmid DNA obtained from $K$. pneumoniae strains and E. coli transconjugant as well as transformants was digested with EcoRI or SphI (Promega). Digested plasmid DNA was separated on a $0.8 \%$ agarose gel in $0.5 \times$ Tris-borate-EDTA for $3 \mathrm{~h}$ at $70 \mathrm{~V}$. A $1 \mathrm{~kb}$ DNA ladder (Promega) and $\lambda$ DNA digested with HindIII (Promega) were used as DNA markers.

\section{RESULTS AND DISCUSSION}

\section{Antimicrobial susceptibility}

All $51 \mathrm{~K}$. pneumoniae strains tested were sensitive to imipenem, except strain KB10, which showed intermediate resistance to imipenem. The majority ( 49 of 51 , or $96 \%$ ) of the strains showed resistance to ampicillin. The resistance rates for the other antibiotics tested using the disc diffusion method are listed in Table 1. Previously published studies on Malaysian K. pneumoniae isolates (Loh et al., 2007; Parasakthi et al., 2000) did not include some of the antibiotics used in this study such as piperacillin, cefepime, aztreonam, tetracycline, streptomycin, kanamycin, chlor- amphenicol and nalidixic acid. However, a similar trend of very high and very low resistance rates was observed for ampicillin and imipenem, respectively. This is also in concordance with the latest 2008 Malaysian National Surveillance on Antibiotic Resistance Report (available online at http://www.imr.gov.my/report/nsar.htm), which stated a very low imipenem resistance rate of $0.5 \%$ and a very high ampicillin resistance rate of $98.8 \%$, which is not surprising as Klebsiella is known to be intrinsically resistant to ampicillin.

The resistance rates for gentamicin, amikacin and amoxicillin-clavulanic acid were, however, lower than those in the earlier studies on K. pneumoniae strains from Malaysia in 1999 (Parasakthi et al., 2000) and 2000-2004 (Loh et al., 2007). The strains used in this study were isolated from sporadic cases, in contrast to the strains used by Parasakthi et al. (2000), who investigated only nine outbreak strains isolated from a local University Hospital; all nine strains were reported to be resistant to gentamicin, amikacin and amoxicillin-clavulanic acid. Loh et al. (2007) reported the resistance rates from another public Malaysian hospital but over a 4 -year period. They showed that the resistance rate for combined amoxicillin-clavulanic acid and ampicillinsulbactam was $58.4 \%$ whereas the resistance rate for aminoglycosides (combined gentamicin and amikacin) was $42.5 \%$. These figures are in sharp contrast to the rates of $10 \%, 31 \%$ and $12 \%$ obtained for amoxicillin-clavulanic acid, gentamicin and amikacin, respectively, in this study.

The resistance rates of $K$. pneumoniae to the thirdgeneration cephalosporins ceftazidime and ceftriaxone were lower than those in the study carried out in 1999 (Parasakthi et al., 2000) but were higher than those in the study carried out for the years 2000-2004 (Loh et al.,

Table 1. Antimicrobial susceptibility profiles of all $51 \mathrm{~K}$. pneumoniae isolates used in this study

\begin{tabular}{|lccr|}
\hline Antimicrobial & Sensitive $[\boldsymbol{n}(\mathbf{\%})]$ & Intermediate $[\boldsymbol{n}(\%)]$ & Resistant $[\boldsymbol{n}(\%)]$ \\
\hline Amikacin & $37(73)$ & $8(15)$ & $6(12)$ \\
Ampicillin & 0 & $2(4)$ & $49(96)$ \\
Amoxicillin + clavulanic acid & $27(53)$ & $19(37)$ & $5(10)$ \\
Aztreonam & $26(51)$ & $4(8)$ & $21(41)$ \\
Cefepime & $44(86)$ & $2(4)$ & $5(10)$ \\
Cefoperazone & $25(49)$ & $11(22)$ & $15(29)$ \\
Ceftazidime & $26(51)$ & $4(8)$ & $21(41)$ \\
Ceftriaxone & $28(55)$ & $5(10)$ & $18(35)$ \\
Chloramphenicol & $35(69)$ & $3(6)$ & $13(25)$ \\
Ciprofloxacin & $42(82)$ & $3(6)$ & $6(12)$ \\
Gentamicin & $35(69)$ & 0 & $16(31)$ \\
Imipenem & $50(98)$ & $1(2)$ & 0 \\
Kanamycin & $27(53)$ & $6(12)$ & $18(35)$ \\
Nalidixic acid & $27(53)$ & $6(12)$ & $18(35)$ \\
Piperacillin & $8(15)$ & $10(20)$ & $33(65)$ \\
Tetracycline & $36(70)$ & $4(8)$ & $11(22)$ \\
Trimethoprim + sulfamethoxazole & $35(69)$ & $1(2)$ & $15(29)$ \\
Streptomycin & $20(39)$ & $16(31)$ & $15(29)$ \\
\hline
\end{tabular}


2007). Loh et al. (2007) reported fluctuating resistance rates of $18-21 \%$ to third-generation cephalosporins (combined ceftazidime, ceftriaxone and cefotaxime). The 2008 Malaysian National Surveillance on Antibiotic Resistance Report recorded the resistance rates to ceftazidime and ceftriaxone as $22.3 \%$ and $23.4 \%$, respectively (http://www.imr.gov.my/report/nsar.htm). In contrast, our study showed resistance rates for ceftazidime and ceftriaxone of $41 \%$ and $35 \%$, respectively.

The resistance rate of $K$. pneumoniae strains to ciprofloxacin in Malaysia is still relatively low (12\%) when compared to Thailand, where a rate of $43 \%$ had been reported (Chaikittisuk \& Munsrichoom, 2007). The resistance rates of the Malaysian K. pneumoniae strains to amikacin, chloramphenicol and trimethoprim-sulfamethoxazole were also lower than those of strains isolated from Thailand (resistance rates of $58 \%, 45 \%$ and $74 \%$, respectively; Chaikittisuk \& Munsrichoom, 2007).

Among the $51 \mathrm{~K}$. pneumoniae strains, 27 were MDR (i.e. resistant to three or more classes of antimicrobial agents). The rate of MDR K. pneumoniae strains in Malaysia is relatively low (53\%) when compared to the $94 \%$ MDR rate reported in India (Manchanda et al., 2005).

Using the DDST, only 12 ESBL-producing strains were detected. However, based on the phenotypic confirmatory test, 24 strains were found to be ESBL producers. The phenotypic confirmatory test was found to be more efficient in determining ESBLs than the DDST. Although the DDST was considered a reliable method for ESBL detection (Tofteland et al., 2007), it has been known to suffer from the non-standardization of the distance of disc placement for optimal sensitivity leading to variation from one laboratory to another (Bradford, 2001). Large discrepancies between the different ESBL detection methods were observed and could partly be due to problems in determining the zone of inhibition, especially for cephalosporins, where strains that were noted as negative nevertheless had zones of inhibition which fell outside the range determined by the CLSI. Tofteland et al. (2007) had previously reported discrepancies between different detection methods where two TEM-128 strains, which had a CTX-M9-like phenotype, were found to score negative using the ceftazidime combined disc method.

\section{PCR detection of ESBL-encoding genes}

Using specific primers, PCR was carried out on the genomic and plasmid DNA of the $51 \mathrm{~K}$. pneumoniae strains for the following ESBL-encoding genes: $b l a_{\mathrm{TEM}}$, $b l a_{\mathrm{SHV}}, b l a_{\mathrm{OXA}}, b l a_{\mathrm{CTX}-\mathrm{M}}, \quad b l a_{\mathrm{VEB}}, b l a_{\mathrm{IMP}}, b l a_{\mathrm{VIM}}$ and $b l a_{\mathrm{DHA}}$. The majority of the strains (46 of 51) showed positive amplification for $b l a_{\mathrm{SHV}}$. This was followed by bla $a_{\text {СтХ-м }}$ (positive in 19 of 51 strains), bla $a_{\text {OXA }}$ (5 strains) and $b l a_{\text {TEM }}$ (4 strains). Palasubramaniam et al. (2005) had previously reported the prevalence of the $b l a_{\mathrm{SHV}}$ gene in $K$. pneumoniae strains isolated from a Malaysian hospital.
Thus, $b a_{\mathrm{SHV}}$ appeared to be more common among Malaysian K. pneumoniae strains even though $b l a_{\text {CTX-M }}$ is now reported to be the most prevalent ESBL gene worldwide, replacing TEM and SHV $\beta$-lactamases in many European countries (Livermore et al., 2007).

Sequencing of ten of the $b l_{\mathrm{SHV}}$ amplicons identified eight as SHV-11, one as SHV-12 and the remaining amplicon as SHV-1. Sequence analysis of all four bla $a_{\text {TEM }}$ amplicons identified them as TEM-1 whereas all five $b l a_{\text {OXA }}$ amplicons were identified as OXA-1. In the case of $b l a_{\text {CTX-M }}$, sequences obtained identified 6 of the 19 amplified products as CTX-M-15. It was, however, not possible to group the remaining $13 b{ }_{b} a_{\mathrm{CTX}-\mathrm{M}}$ amplicons obtained as the primers that were used did not amplify the entire $b l a_{\mathrm{CTX}-\mathrm{M}}$ reading frame. The subsequent use of primers 1R, 1,8F, 2F, 2R, 8R, 9F and 9R (Ensor et al., 2007) to further subgroup the $13 b a_{\text {CTX-M }}$ genes could only indicate that they did not belong to groups 1,2, 8/25 and 9 .

Out of the $46 b l a_{\mathrm{SHV}}$-positive strains, 16 also harboured $b l a_{\mathrm{CTX}-\mathrm{M}}$ and 2 were positive for $b l a_{\mathrm{OXA}-1}$. Two strains, $\mathrm{KB} 16$ and $\mathrm{KB} 35$, had three ESBL-encoding genes, i.e. $b l a_{\mathrm{SHV}}, b l a_{\mathrm{OXA}-1}$ and $b l a_{\mathrm{CTX}-\mathrm{M}-15}$. The presence of multiple ESBL-encoding genes in K. pneumoniae has been reported by Romero et al. (2007), and Livermore et al. (2007) had indicated that $b l a_{\mathrm{CTX}-\mathrm{M}-15}$ was genetically linked with $b l a_{\text {OXA-1 }}$.

No amplification product was obtained with primers that were specific for the $b l a_{\mathrm{VEB}}, b l a_{\mathrm{IMP}}$ and $b l a_{\mathrm{DHA}}$ genes. The majority of the ESBL-encoding genes were detected from plasmid DNA (i.e. $40 b l a_{\mathrm{SHV}}, 6 b l a_{\mathrm{CTX}-\mathrm{M}}$ and $3 b l a_{\mathrm{OXA}}$ ), inferring that most of the ESBL genes were plasmid-borne. PCR amplifications with extracted plasmid DNA as template were carried out in parallel with additional $16 \mathrm{~S}$ rRNA primers to preclude chromosomal DNA contamination.

Using PCR, class 1 integron-encoded intI1 integrases were found in 21 of the $51 \mathrm{~K}$. pneumoniae strains whereas neither class 2 nor class 3 integron-encoded integrases were detected. In 12 of the 21 intI1-positive strains, the gene cassettes aadB (in 7 isolates), aadA2-dhfrhI (in 2 isolates) and aadA2-orfF-dhfrXII (in 3 isolates) were amplified and identified by sequencing, with $a a d B$ encoding resistance to gentamicin, kanamycin and tobramycin, aadA2 encoding resistance to streptomycin, and $d h f r X I I$ encoding resistance to trimethoprim (Daikos et al., 2007).

\section{Transfer of resistance determinants}

Conjugation experiments were performed for four nalidixic acid-sensitive $K$. pneumoniae strains with $E$. coli JM109 as recipient. Plasmid transfer via conjugation with selection for the ESBL phenotype to E. coli JM109 was successful for only one out of four strains. The resulting single E. coli transconjugant showed resistance to aztreonam as well as gentamicin and was confirmed as an ESBL producer using the DDST. PCR of DNA extracted from the 


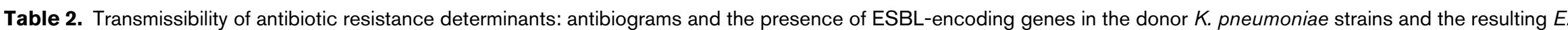
coli transconjugants and transformants

\begin{tabular}{|c|c|c|c|c|c|}
\hline $\begin{array}{l}\text { K. pneumoniae } \\
\text { strain no. }\end{array}$ & Resistance profile ${ }^{\star}$ of $K$. pneumoniae donor & $\begin{array}{l}\text { ESBL gene(s) detected } \\
\text { in K. pneumoniae }\end{array}$ & $\begin{array}{c}\text { Mode of } \\
\text { transmission }\end{array}$ & $\begin{array}{l}\text { Resistance profile }{ }^{\star} \text { of } E \text {. coli } \\
\text { transformant/transconjugant }\end{array}$ & $\begin{array}{l}\text { ESBL gene(s) } \\
\text { transferred }\end{array}$ \\
\hline KB36 & AMP, PIP, CAZ, CRO, CFP, ATM, KAN, GEN & $b l a_{\mathrm{SHV}}, b l a_{\mathrm{TEM}}$ & Conjugation & AMP, ATM, GEN & $b l a_{\mathrm{SHV}}, b l a_{\mathrm{TEM}}$ \\
\hline KB1 & AMP, PIP, TET, KAN, GEN, CIP, NAL & $b l a_{\mathrm{SHV}}, b l a_{\mathrm{CTX}-\mathrm{M}}$ & Transformation & AMP, PIP, TET & $b l a_{\mathrm{SHV}}, b l a_{\mathrm{CTX}-\mathrm{M}}$ \\
\hline KB5 & AMP, PIP, CAZ, ATM, TET, KAN, GEN, AMK & $b l a_{\mathrm{SHV}}$ & Transformation & AMP, PIP, TET, CHL & $b l a_{\mathrm{SHV}}$ \\
\hline KB21 & $\begin{array}{l}\text { CRO, AMP, NAL, PIP, AMK, ATM, CFP, CAZ, } \\
\text { KAN, GEN, TET, CHL, SXT, NAL }\end{array}$ & $b l a_{\mathrm{SHV}}$ & Transformation & AMP, PIP, GEN, TET, CHL & $b l a_{\mathrm{SHV}}$ \\
\hline KB22 & $\begin{array}{l}\text { AMP, PIP, CAZ, CRO, TET, STR, KAN, GEN, } \\
\text { CIP, CHL, SXT, NAL }\end{array}$ & $b l a_{\mathrm{SHV}}$ & Transformation & AMP, PIP, TET, GEN, CIP, NAL & $b l a_{\mathrm{SHV}}$ \\
\hline KB24 & $\begin{array}{l}\text { AMP, PIP, CAZ, CRO, CFP, ATM, TET, KAN, } \\
\text { GEN, AMK, CHL, SXT, NAL }\end{array}$ & $b l a_{\text {TEM }}$ & Transformation & AMP, PIP, CHL & $b l a_{\mathrm{TEM}}$ \\
\hline KB35 & $\begin{array}{l}\text { AMP, PIP, CAZ, CRO, FEP, CFP, ATM, STR, } \\
\text { GEN, CHL, NAL }\end{array}$ & $b l a_{\mathrm{SHV}}, b l a_{\mathrm{CTX}-\mathrm{M}}, b l a_{\mathrm{OXA}}$ & Transformation & AMP, PIP, CHL & $b l a_{\mathrm{SHV}}$ \\
\hline KB45 & $\begin{array}{l}\text { AMP, PIP, CAZ, CRO, FEP, STR, KAN, GEN, } \\
\text { CHL, SXT, NAL, ATM }\end{array}$ & $b l a_{\mathrm{SHV}}, b l a_{\mathrm{CTX}-\mathrm{M}}$ & Transformation & AMP, PIP, CHL, SXT, NAL & $b l a_{\mathrm{SHV}}, b l a_{\mathrm{CTX}-\mathrm{M}}$ \\
\hline KB50 & AMP, PIP, TET, STR, GEN, CIP, SXT, NAL & $b l a_{\mathrm{SHV}}$ & Transformation & AMP, PIP, TET, SXT & $b l a_{\mathrm{SHV}}$ \\
\hline
\end{tabular}

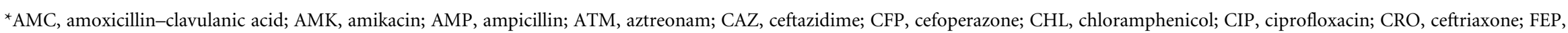
cefepime; GEN, gentamicin; KAN, kanamycin; NAL, nalidixic acid; PIP, piperacillin; STR, streptomycin; SXT, trimethoprim-sulfamethoxazole; TET, tetracycline. 
E. coli transconjugant showed that $b l a_{\mathrm{TEM}-1}, b l a_{\mathrm{SHV}}$ and intI1 genes were successfully transferred to the transconjugant (Table 2).

Transformation studies were performed for ten $K$. pneumoniae strains that harboured plasmids. Plasmid transfer of the ESBL phenotype by electroporation to $E$. coli $\mathrm{DH} 10 \mathrm{~B}$ was successful in eight out of the ten strains. All resulting DH10B transformants were resistant to $\beta$ lactam antibiotics (ampicillin and piperacillin). The majority of the transformants (five out of eight) were also resistant to tetracycline and chloramphenicol, indicating that these resistance determinants were likely plasmidencoded and were thus co-transferred (Table 2).

Most of the ESBL-encoding genes detected in the parental $K$. pneumoniae strains were successfully transferred into the recipient E. coli $\mathrm{DH} 10 \mathrm{~B}$, except for the $b l a_{\mathrm{SHV}}$ and $b l a_{\mathrm{OXA}-1}$ genes in strain KB35.

Both conjugation and transformation experiments had indicated that some of the ESBL-encoding genes (in particular $\left.b a_{\mathrm{SHV}}\right)$ were plasmid-encoded and transmissible. The results indicated the high mobility of the ESBLencoding genes in $K$. pneumoniae in agreement with observations made by Chanawong et al. (2002).

Preliminary plasmid analysis results indicated that 11 of the $K$. pneumoniae strains may not harbour any plasmids. Plasmids of sizes ranging from 3 to $310 \mathrm{~kb}$ were, however, detected in the other $40 \mathrm{~K}$. pneumoniae strains and efforts are on-going to further characterize these plasmids, in particular those from the MDR strains.

\section{Genotyping by PCR and PFGE}

The genetic relatedness of the $51 \mathrm{~K}$. pneumoniae strains was determined by PFGE as well as the PCR-based RAPD, ERIC-PCR and REP-PCR. With RAPD using the OPAB11 primer, the 51 strains were subtyped into 49 unique profiles $(F=0.30-1.0)$. Subtyping using ERIC- and REPPCR resulted in $46(F=0.47-1.0)$ and $50(F=0.50-1.0)$ different profiles, respectively. Genomic DNA from $49 \mathrm{~K}$. pneumoniae strains that was digested with $X b a \mathrm{I}$ and separated by PFGE resulted in 47 distinct pulsed-field profiles $(F=0.54-1.0)$. Two other $K$. pneumoniae strains, KB42 and KB49, could not be typed by PFGE despite repeated attempts.

Thus, genotyping of the $51 \mathrm{~K}$. pneumoniae clinical strains by ERIC-PCR, RAPD, REP-PCR and PFGE showed that they were genetically diverse and heterogeneous. This was expected as the $K$. pneumoniae strains in this study were isolated from different places and sources and probably belong to various serotypes. Ben-Hamouda et al. (2003) and Pai et al. (2004) also reported similar heterogeneity among $K$. pneumoniae clinical strains.

In general, no direct correlation between DNA profiles and antibiotic susceptibility patterns was observed. Strains with identical DNA profiles frequently belonged to different antibiotypes. The Malaysian MDR K. pneumoniae clinical strains studied were genetically very diverse and heterogeneous suggesting that multiple subtypes of the species were involved in infection. Carbapenemase production was not evident in all strains studied. Although bla $a_{\mathrm{SHV}}$ appeared to be the predominant ESBL-encoding gene detected in Malaysia, bla $a_{\mathrm{CTX}-\mathrm{M}}$ is gaining in importance. This study also showed the potential role of integrons and plasmids in the spread of ESBL-encoding genes and other antibiotic resistance genes in $K$. pneumoniae.

\section{ACKNOWLEDGEMENTS}

This work was partially funded by grants from the Malaysian Toray Science Foundation, the Malaysian Ministry of Science, Technology and Innovation (MOSTI) and the University of Malaya. We thank Nurahan Maning (Kota Bharu Hospital), Tan Eng Am (Ipoh Hospital) and Zubaidah Abdul Wahab (Kuala Lumpur Hospital) for kindly providing strains for this study. K.T.L. was supported by NSF from MOSTI.

\section{REFERENCES}

Ben-Hamouda, T., Foulan, T., Ben-Cheikh-Masmoudi, A., Fendri, C., Belhadj, O. \& Ben-Mahrez, K. (2003). Molecular epidemiology of an outbreak of multiresistant Klebsiella pneumoniae in a Tunisan neonatal ward. J Med Microbiol 52, 427-433.

Bradford, P. A. (2001). Extended-spectrum $\beta$-lactamases in the 21 st century: characterization, epidemiology, and detection of this important resistance threat. Clin Microbiol Rev 14, 933-951.

Cartelle, M., Tomas, M. D. M., Pertega, S., Beceiro, A., Dominguez, M. A., Velasco, D., Molina, F., Villanueva, R. \& Bou, G. (2004). Risk factors for colonization and infection in a hospital outbreak caused by a strain of Klebsiella pneumoniae with reduced susceptibility to extended-spectrum cephalosporins. J Clin Microbiol 42, 4242-4249.

Chaikittisuk, N. \& Munsrichoom, A. (2007). Extended-spectrum $\beta$ lactamase producing Escherichia coli and Klebsiella pneumoniae in children at Queen Sirikit National Institute of Child Health. J Infect Dis Antimicrob Agents 24, 107-115.

Chanawong, A., M'Zali, F. H., Heritage, J., Xiong, J. H. \& Hawkey, P. M. (2002). Three cefotaximes, CTX-M-9, CTX-M-13, and CTX-M14, among Enterobacteriaceae in the People's Republic of China. Antimicrob Agents Chemother 46, 630-637.

CLSI (2006). Performance Standards for Antimicrobial Susceptibility Testing, 16th Informational Supplement. Wayne, PA: Clinical and Laboratory Standards Institute.

Conceição, T., Brízio, A., Duarte, A., Lito, L. M., Melo Cristino, J. \& Salgado, M. J. (2005). First description of CTX-M-15-producing Klebsiella pneumoniae in Portugal. Antimicrob Agents Chemother 49, 477-478.

Daikos, G. L., Kosmidis, C., Tassios, P. T., Petrikkos, G., Vasilakopoulou, A., Psychogiou, M., Stefanou, I., Avlami, A. \& Katsilambros, N. (2007). Enterobacteriaceae bloodstream infections: presence of integrons, risk factors and outcome. Antimicrob Agents Chemother 51, 2366-2372.

de Bruijn, F. J. (1992). Use of repetitive (repetitive extragenic palindromic and enterobacterial repetitive intergeneric consensus) sequences and the polymerase chain reaction to fingerprint the genomes of Rhizobium meliloti isolates and other soil bacteria. Appl Environ Microbiol 58, 2180-2187. 
Ensor, V. M., Livermore, D. M. \& Hawkey, P. M. (2007). A novel reverse-line hybridization assay for identifying genotypes of CTX-Mtype extended-spectrum $\beta$-lactamases. J Antimicrob Chemother 59, 387-395.

Giakkoupi, P., Xanthaki, A., Kanelopoulou, M., Vlahaki, A., Mirigou, V., Kontou, S., Papafraggas, E., Malamou-Lada, H., Tzouvelekis, L. S. \& other authors (2003). VIM-1 metallo- $\beta$ lactamase-producing Klebsiella pneumoniae in Greek hospitals. J Clin Microbiol 41, 3893-3896.

Jarlier, V., Nicolas-Chanoine, M. H., Fournier, G. \& Philippon, A. (1988). Extended-broad spectrum $\beta$-lactamases conferring transferable resistance to newer $\beta$-lactam agents in Enterobacteriaceae: hospital prevalence and susceptibility patterns. Rev Infect Dis 10, 867-878.

Jiang, X., Zhang, Z., Li, M., Zhou, D., Ruan, F. \& Lu, R. (2006). Detection of extended-spectrum $\beta$-lactamases in clinical strains of Pseudomonas aeruginosa. Antimicrob Agents Chemother 50, 29902995.

Kang, H. Y., Young, S. J., Jae, Y. O., Sung, H. T., Chui, H. C., Dong, C. M., Won, K. L., Yoo, C. L., Sung, Y. S. \& other authors (2005). Characterization of antimicrobial resistance and class 1 integrons found in Escherichia coli strains from humans and animals in Korea. J Antimicrob Chemother 55, 639-644.

Latha, R., Suryanarayanan, T. S. \& Swaminathan, M. S. (2004). Genetic diversity in Acremonium endophytes isolated from warmseason grasses as revealed by RAPD markers. J Plant Biochem Biotechnol 13, 39-42.

Livermore, D. M., Canton, R., Gniadkowski, M., Nordmann, P., Rossolini, G. M., Arlet, G., Ayala, J., Coque, T. M., Zdanowicz, I. K. \& other authors (2007). CTX-M: changing the face of ESBLs in Europe. $J$ Antimicrob Chemother 59, 165-174.

Loh, L. C., Chin, H. K., Chong, Y. Y., Jeyaratnam, A., Raman, S., Vijayasingham, P., Thayaparan, T. \& Kumar, S. (2007). Klebsiella pneumoniae respiratory strains from 2000 to 2004 in a Malaysia hospital: characteristics and relation to hospital antibiotics consumption. Singapore Med J 48, 813-818.

Machado, E., Canton, R., Banquero, F., Galan, J. C., Rollan, A., Peixe, L. \& Coque, T. M. (2005). Integron content of extended-spectrum $\beta$ lactamases producing Escherichia coli strains over 12 years in a single hospital in Madrid, Spain. Antimicrob Agents Chemother 49, 1823-1829.

Manchanda, V., Goyal, S. R., Kumar, A. \& Thukral, S. S. (2005). Phenotypic characteristics of clinical strains of Klebsiella pneumoniae and evaluation of available phenotypic techniques for detection of extended spectrum beta-lactamases. Indian J Med Res 122, 330-337.

Navia, M. M., Capitang, L., Ruiz, J., Vargas, M., Urassa, H., Schellemberh, D., Gascon, J. \& Vila, J. (1999). Typing and characterization of mechanisms of resistance of Shigella spp. isolated from feces of children under 5 years of age from Ifakara, Tanzania. J Clin Microbiol 37, 3113-3117.
Oliver, A., Weigel, L. M., Rasheed, J. K., McGowan, J. E., Jr, Raney, P. \& Tenover, F. C. (2002). Mechanisms of decreased susceptibility of cefpodoxime in Escherichia coli. Antimicrob Agents Chemother 46, 3829-3836.

Pagani, L., Amico, E. D., Migliavacca, R., Andrea, M. M. D., Giacobone, E., Amicosante, G., Romero, E. \& Rossolini, G. M. (2003). Multiple CTX-M extended-spectrum $\beta$-lactamases in nosocomial strains of Enterobacteriaceae from a hospital in Northern Italy. J Clin Microbiol 41, 4264-4269.

Pai, H., Kang, C. I., Byeon, J. H., Lee, K. D., Park, W. B., Kim, H. B., Kim, E. C., Oh, M. D. \& Kang, W. C. (2004). Epidemiology and clinical features of bloodstream infections caused by AmpC-type $\beta$-lactamaseproducing Klebsiella pneumoniae. Antimicrob Agents Chemother 48, 3720-3728.

Palasubramaniam, S., Subramaniam, G., Muniandy, S. \& Parasakthi, N. (2005). SHV-5 extended-spectrum beta-lactamase from Klebsiella pneumoniae associated with a nosocomial outbreak in a paediatric oncology unit in Malaysia. Int J Infect Dis 9, 170-172.

Parasakthi, N., Vadivelu, J., Ariffin, H., Iyer, L., Palasubramaniam, S. \& Arasu, A. (2000). Epidemiology and molecular characterization of nosocomially transmitted multidrug-resistant Klebsiella pneumoniae. Int J Infect Dis 4, 123-128.

Podschun, R. \& Ullmann, U. (1998). Klebsiella spp. as nosocomial pathogens: epidemiology, taxonomy, typing methods, and pathogenicity factors. Clin Microbiol Rev 11, 589-603.

Romero, E. D. V., Padila, T. P., Hernandez, A. H., Grande, R. P., Vazquez, M. F., Garcia, I. G., Rodrigurz, J. A. G. \& Bellido, J. L. M. (2007). Prevalence of clinical strains of Escherichia coli and Klebsiella spp. producing multiple extended-spectrum $\beta$-lactamases. Diagn Microbiol Infect Dis 59, 433-437.

Senda, K., Arakawa, Y., Ichiyama, S., Nakashima, K., Ito, H., Ohsuka, S., Shimokata, K., Kato, N. \& Ohta, M. (1996). PCR detection of metallo- $\beta$ lactamase gene $\left(b a_{\mathrm{IMP}}\right)$ in Gram-negative rods resistant to broadspectrum $\beta$-lactams. J Clin Microbiol 34, 2909-2913.

Singh, A., Goering, R. V., Simjee, S., Foley, S. L. \& Zervos, M. J. (2006). Application of molecular techniques to the study of hospital infection. Clin Microbiol Rev 19, 512-530.

Thong, K. L., Lai, K. S., Puthucheary, S. D., Koh, Y. T., Ahmad, N. \& Yasin, R. M. (2007). Subtyping of Salmonella enterica serovar Muenchen by pulsed-field gel electrophoresis, plasmid profiling and antimicrobial susceptibility testing. Malay J Sci 26, 1-13.

Tofteland, S., Haldorsen, B., Dahl, K. H., Simonsen, G. S., Steinbakk, M., Walsh, T. R., Sundsfjord, A. \& the Norwegian ESBL Study Group (2007). Effects of phenotype and genotype on methods for detection of extended-spectrum- $\beta$-lactamase-producing clinical strains of Escherichia coli and Klebsiella pneumoniae in Norway. J Clin Microbiol 45, 199-205. 